\title{
Pathologic N1 disease in lung cancer: the segmental and subsegmental lymph nodes
}

\author{
Marc Riquet, Ciprian Pricopi, Giuseppe Mangiameli, Alex Arame, Alain Badia, Françoise Le Pimpec \\ Barthes
}

General Thoracic Surgery Department, Georges Pompidou European Hospital, Paris, France

Correspondence to: Marc Riquet. Georges Pompidou European Hospital, 20 rue Leblanc, Paris 75908, France. Email: marc.riquet@egp.aphp.fr.

Provenance: This is an invited Editorial commissioned by the Section Editor Laura Chiara Guglielmetti (Cantonal Hospital Winterthur, Kantonsspital Winterthur, Switzerland).

Comment on: Wang X, Yan S, Lv C, et al. Impact of omission of intrapulmonary lymph node retrieval on outcome evaluation of lung cancer patients without lymph node metastasis: a propensity score matching analysis. Clin Lung Cancer 2017. [Epub ahead of print].

Submitted Oct 02, 2017. Accepted for publication Oct 16, 2017.

doi: $10.21037 /$ jtd.2017.10.119

View this article at: http://dx.doi.org/10.21037/jtd.2017.10.119

N1 disease represents a heterogeneous group of non-small cell lung carcinoma (NSCLC). Pathologic N1 disease may involve one or more lymph node ( $\mathrm{LN})$ in the lung classified by Mountain and Dressler (1) in five stations corresponding to their anatomical locations: the hilar LNs, the Interlobar LNs, the lobar LNs, the segmental LNs and the subsegmental LNs being termed station 10, 11, 12, 13 and 14, respectively. In the seventh edition of the TNM classification for lung cancer (2), N1 disease was classified in two zones, hilar/interlobar zone regrouping stations 10 and 11 and peripheral zone regrouping stations 12,13 and 14 .

Wang and coworkers (3) questioned the impact of omission of station 13 and $14 \mathrm{LN}$ retrieval on outcome evaluation of NSCLC in a series of 435 post-surgery pN0 patients. LNs from stations 10 to 12 had been routinely collected during the operation in all patients but segmental station 13 and subsegmental station 14 had been retrieved at the surgeons' discretion. Segmental station 13 was collected from 163 patients $(95.9 \%)$, and subsegmental station 14 was collected from 103 patients (60.6\%). Overall survival (OS) and disease-free survival (DFS) was significantly improved in the 13-14 station group compared to the other (5-year OS rate, $89.3 \%$ vs. $77.4 \%, \mathrm{P}=0.027$; 5 -year DFS rate, $81.4 \%$ vs. $67.4 \%, \mathrm{P}=0.021)$. They concluded that $\mathrm{pN} 0$ patients with station 13 and 14 collected were truly pN0, whereas patients with station 13 and $14 \mathrm{pN} 1$ involvement were probably present among the $\mathrm{pN} 0$ patients without that $\mathrm{LN}$ retrieval. Their study draws attention on the importance of intrapulmonary $\mathrm{LN}$ collection for accurate diagnosis of true pN0. The role of segmental LNs in the pathological staging of NSCLC had also been previously underlined by $\mathrm{Li}$ and coworkers (4), and Huang and coworkers (5) who confirmed the presence of involved LNs in those stations. $\mathrm{Li}$ and coworkers (4) observed that in 113 patients ( $\mathrm{pN} 0 \mathrm{n}=68, \mathrm{pN} 1$ $\mathrm{n}=16$ and $\mathrm{pN} 2 \mathrm{n}=29), 6$ patients $(37.5 \%$ of $\mathrm{pN} 1)$ would have been down-staged to $\mathrm{N} 0$, and that two cases of multiplezone $\mathrm{pN} 1$ disease would have been misdiagnosed as singlezone N1 disease without segmental LNs dissection. Similar results were reported by Huang and coworkers (5) who discovered that among 370 patients ( $\mathrm{pN} 0 \mathrm{n}=238$, pN1 $\mathrm{n}=62$ cases and $\mathrm{pN} 2 \mathrm{n}=69), 16$ patients $(25.8 \%$ of $\mathrm{pN} 1)$ would have been down-staged to N0, and that five cases of multiple-station $\mathrm{N} 1$ disease would have been misdiagnosed as single-station $\mathrm{N} 1$ disease.

In fact, these intrapulmonary LNs deserve special attention because they occupy an original place not only with regard to the prognosis of the NSCLCs when they are metastatic but also because of their anatomical and pathogenic characteristics

\section{Considerations on the prognosis of pN1 NSCLC}

The number of involved LNs or the LN-stations in the lung may influence the 5 -year survival rates. We reviewed 1,174 patients in 1999 (6): $50.25 \%$ were pN0, $21.8 \%$ $\mathrm{pN} 1$ and $27.95 \%$ were $\mathrm{pN} 2$. The 5 -year survival was 
significantly better when N1 involvement was intralobar (levels 12 and 13, $\mathrm{n}=102$ ), as compared with extralobar (hilar) involvement (levels 10 and 11, $\mathrm{n}=154$ ): $53.6 \%$ vs. $38.5 \%(\mathrm{P}=0.02)$. Ten years later, Demir and coworkers reviewed $540 \mathrm{pN} 1$ patients (7). The 5 -year survival rates for patients with hilar N1 (station 10), interlobar (station 11), and peripheral N1 (stations 12 to 14) involvement were $39 \%, 51 \%$ and $53 \%$, respectively. Patients with hilar LN metastasis showed a shorter survival period than patients with peripheral $\mathrm{LN}$ involvement $(\mathrm{P}=0.02)$. Patients with hilar zone $\mathrm{N} 1$ (stations 10 and 11) involvement tended to show poorer survival than patients with peripheral zone N1 (12 to 14$)$ metastasis $(\mathrm{P}=0.08)$. The same kinds of results have subsequently been commonly reported. Maeshima and coworkers (8) reported that the 5-year DFS rates for pN0, level 13/14 pN1, lobar (level 12), interlobar (level 11), and hilar (level 10) pN1 were 90.5\%, 69.4\%, 46.4\%, 46.7\% and $37 \%$, respectively. Reviewing stage II (T1a-T2bN1M0) NSCLC, Li and coworkers (9) observed that peripheral zone $\mathrm{LN}$ involvement was a statistically significant indicators of higher OS and DFS by univariate analyses, and Liu and coworkers (10), that hilar/interlobar nodal zone involvement was significant predictors for worse OS by multivariate analysis $(\mathrm{P}=0.001)$. Rena and coworkers (11) reported that the 5 -year survival rates for $\mathrm{pN} 0$, level $13+14$, level $11+12$, level $10 \mathrm{pN} 1$, and $\mathrm{pN} 2$ was $93 \%, 81 \%, 58 \%$, $48 \%$ and $25 \%$, respectively.

Concerning the peripheral LNS, some curiosities of the prognostic value of their invasion raise some questions. In the previous papers (8-11), patients who had only level $13 / 14 \mathrm{LN}$ metastasis seemed to have an intermediate 5 -year DFS rate between that of patients with pN0 status and other patients with pN1 status. However, we observed that Intralobar pN1 5 -year survival was similar to that of pN0 (53.6\% vs. $56.5 \%, \mathrm{P}=0.01)$, and that extralobar $\mathrm{pN} 1$ 5 -year survival was comparable with that of $\mathrm{pN} 2$ (38.5 vs. $28.3 \%, \mathrm{P}=0.01)$ when $\mathrm{pN} 2$ was only located in one station of the ipsilateral mediastinum (6). Wang and coworkers (3) have reported other results that prompt reflection. They observed that the patients whose intrapulmonary nodes were retrieved from 2 stations (13 and 14), showed better survival than those without any intrapulmonary LNs retrieved (5-year OS rate, $90.3 \%$ vs. $77.3 \%, \mathrm{P}=0.010$ ). In contrary, survival of patients from whom intrapulmonary LNs were retrieved from only one station was not significantly different when compared to that of patients without any retrieved intrapulmonary LNs (5-year OS rate, $85.5 \%$ vs. $77.3 \%, \mathrm{P}=0.147$ ).
In a more recent study, we analyzed a larger series of $\mathrm{pN} 1$ patients $(\mathrm{n}=450)(12)$. Only one station was metastatic in 340 patients $(75.6 \%$, single station disease) and two stations or more were involved in 110 patients $(24.4 \%$, multiple station disease). The presence of intralobar metastatic LN (station 12-13-14) did not impact the 5-year survival $(\mathrm{P}=0.71)$. The location of metastatic stations was of prognostic significance only in case of multi-station disease, with hilar (station 10) involvement. Thus, since threequarters of patients had a single station with metastatic LNs, it is not surprising that the impact on survival could be equivalent to those of Wang and coworkers (3) when they indicated that the difference is not significant in cases where only one station has been recovered (possible pN1) compared to cases where no intrapulmonary LN recovery has been performed. This may also support the finding that pN1 involvement of stations 13 or 14, when isolated, shares a prognosis similar to that of $\mathrm{pN} 0$ patients. Also, it may be possible, as previously suggested (6), that $\mathrm{pN} 1$ disease is a compound of two subgroups: one located peripherally inside the lobes behaving as uninvolved $\mathrm{LN}$ (pN0), and the other (extralobar or hilar) behaving like an early stage of N2 disease. Those two groups correspond to the two zones (2), hilar/interlobar zone (stations 10 and 11) and peripheral zone (stations 12, 13 and 14). This particularity of the prognosis of the peripheral LNs could be correlated with their anatomical, embryological and pathogenetic aspects.

\section{Peripheral LN: anatomy, subpleural LNs, embryology and pathogenesis}

Anatomically, the number of peripheral LNs varies. Wang and coworkers (3) collected a total of 5.0 3.0 (mean $\pm \mathrm{SD}$ ) intrapulmonary LNs, the study concerned pN0 patients. This included 3.1 \pm 1.9 nodes from station 13 and $2.0 \pm 2.2$ nodes from station 14 . In case of $\mathrm{pN} 1$ patient, metastasis can be found in about $60 \%$ of cases. In the paper of Rena and coworkers (11) the median number of examined level $13+14$ LNs was 2 (range, $0-6$ ) and 57\% of $\mathrm{pN} 1$ patients had metastasis at that level. Maeshima and coworkers (8) found a median number of examined 13/14 LNs of 3 (range, 0-22; 13/14 LNs), and metastases to these LNs were detected in $61 \%$ of patients who had $\mathrm{pN} 1$ status. In the series reviewing $\mathrm{pN} 0, \mathrm{pN} 2$ and $\mathrm{pN} 1$ patients, the frequency of segmental LN involvement is not so high. Huang and coworkers (5) reported that the detection rates of hilar nodes, interlobar nodes, lobar nodes and segmental nodes were $69.7 \%, 86.8 \%, 84.0 \%$, 
$67.0 \%$, respectively. The metastasis rates of hilar nodes, interlobar nodes, lobar nodes and segmental nodes were $6.5 \%, 10.8 \%, 15.7 \%$ and $10.3 \%$, respectively. In their paper, $\mathrm{Li}$ and coworkers (4) mentioned that the detection rates of hilar nodes, interlobar nodes, lobar nodes and segmental nodes were $61.1 \%, 85.0 \%, 75.2 \%$ and $80.5 \%$, respectively, and that the metastasis rates were $5.3 \%$, $10.5 \%, 16.8 \%$ and $14.2 \%$, respectively. Thus, the number of LNs was different from an individual to another. This may be observed whatever the LN station (mediastinal or/and intrapulmonary) (13). There were stations where no LN could be found (13). Stations without $\mathrm{LN}$ were also observed in the reports concerning peripheral LNs $(3-5,8,11)$.

To be complete, it should be pointed out that those papers do not mention the most peripheral and distal LNs, the sub-pleural LNs. They lie beneath the visceral pleura and are not very frequent. They first were reported by Greenberg in 1961 (14). They may be misdiagnosed with peripheral NSCLC. Since the development and progress of computed tomographic imaging, those LNs have become increasingly described and are now well-known entities $(15,16)$. They appear as a solitary pulmonary nodular shadow or sometimes as multiple nodules masquerading as carcinoma metastases. These subpleural LNs may also be metastatic (17).

In terms of pathogenesis, peripheral LNs have some other characteristics. Wang and coworkers (3), observed that the tumor-bearing segments harbored $2.8 \pm 2.2 \mathrm{LNs}$ compared to the non-tumor-bearing segments $(2.2 \pm 2.3 \mathrm{LNs}$; $\mathrm{P}=0.006)$. The reason for this difference is unknown, but they thought that factors such as immune response to the tumor and inflammation cannot be ruled out. The fact that more LNs were collected from the tumor-bearing segments than from the none-tumor-bearing segments is similar to another constatation. We also observed (13) that the number of LNs increased in the LN stations when some of them were metastatic. Other hypotheses may help explain that phenomenon. Tertiary lymphoid organs have been reported to appear in lymphatic malformations (18) and chronic inflammatory diseases (19). Tertiary lymphoid organs mimicking LNs that represent sites of lymphoid neogenesis may also develop in most solid cancers (20). We suggest that tertiary "LNs" might also be induced by and associated with tumoral LNs.

Another characteristic also mentioned by Wang and coworkers (2) is that the left lower lobe contained the maximum number of intrapulmonary nodes $(5.7 \pm 2.9)$, followed by the right lower lobe (5.2 \pm 3.0$)$, left upper lobe (5.1 \pm 3.1$)$, right upper lobe $(4.7 \pm 2.8)$, and right middle lobe $(1.7 \pm 0.6)$. The subpleural LNs behave in the same way: $72 \%$ are located in the lower-lobes (15); $25 \%$ are multiple nodes (21). According to Kradin and coworkers (21), most of them may be considered to be acquired highly organized lymphoid nodules formed along interlobular lymphatic drainage routes. In fact, bronchial and bronchiolar lymphoid tissue is sparse at birth (22). Distal LNs, with germinal centers and a definite sinusoidal structure, located along the segmental bronchi lymphatics probably develop during the years following birth in human, as bronchial and bronchiolar lymphoid tissue (system known as bronchus associated lymphoid tissue BALT) does in animals. Because they usually contain only a small number of cells, LNs are difficult to identify within the lung except when they are enlarged owing to a pathologic process (22).

\section{Peripheral LN dissection: who retrieves? Is it the Pathologist or the surgeon?}

For Wang and coworkers (3) and Li and coworkers (9), the procedure of $\mathrm{LN}$ retrieval is at best to be performed by the surgeons. However, many other teams confer this responsibility to pathologists. In our case, a dissection protocol for the recovery of intrapulmonary and mediastinal LNs has been used by pathologists for a long time (6). On the other hand, the role of the surgeon and of him alone is of paramount importance in a particular situation which is not part of what is mentioned by Wang and coworkers (3) and the others. In effect, in all series $(3-5,8,11)$, the resection considered as "lesser resection" is a lobectomy that allows surgeons or pathologists to dissect intralobar LNs in the resected part of the lung. In the case of still lesser resections the quality of surgery actually depends upon the surgeon's skill and this point must be emphasized here. Thus, although this may go beyond the considerations of Wang and coworkers (3), it seems appropriate to broaden the debate on these LNs. LN-dissection completeness is particularly difficult to obtain with sublobar resections (segmentectomy and wedge resection). Intralobar LNdissection, obligatory to be performed by the surgeon, requires care and patience when dissecting along the bronchi after segmentectomy. It is impossible within the remaining lobe during wedge resection and exposes wedge resections to local recurrence risk. Omission of segmental and intralobar LN retrieval might explain the high incidence of loco-regional recurrence observed after segmentectomy 
by Hattori and coworkers (23) and after wedge resection by Stiles and coworkers (24). Given the major impact on the prognosis of peripheral LN metastasis, the absence of intrapulmonary resection of these LNs should be a warning signal when considering local surgical therapy or local nonsurgical procedures such as stereotactic body radiation therapy. Patients receiving stereotactic body radiotherapy for stage I NSCLC are typically staged clinically with PET/CT. Up to $7.6 \%$ of patients may be found to have occult N1 metastasis on pathologic review (25). In conclusion, peripheral LNs must be collected not only for better staging of NSCLC but also for performing a curative operation if a local therapy of peripheral lesions is scheduled.

\section{Acknowledgements}

None.

\section{Footnote}

Conflicts of Interest: The authors have no conflicts of interest to declare.

\section{References}

1. Mountain CF, Dresler CM. Regional lymph node classification for lung cancer staging. Chest 1997;111:1718-23.

2. Rush VW, Asamura H, Watanabe H, et al. The IASLC lung cancer staging project: a proposal for a New Internationnal Lymph Node Map in the forthcoming seventh edition of the TNM classification for lung cancer. J Thorac Oncol 2009;4:568-77.

3. Wang X, Yan S, Lv C, et al. Impact of omission of intrapulmonary lymph node retrieval on outcome evaluation of lung cancer patients without lymph node metastasis: a propensity score matching analysis. Clin Lung Cancer 2017. [Epub ahead of print].

4. Li ZX, Yang H, She KL, et al. The role of segmental nodes in the pathological staging of non-small cell lung cancer. J Cardiothorac Surg 2013;8:225.

5. Huang JD, Li XD, Wang RQ, et al. Importance of segmental lymph nodes in the pathological staging of non-small cell lung cancer. Zhonghua Yi Xue Za Zhi 2017;97:1714-8.

6. Riquet M, Manac'h D, Le Pimpec-Barthes F, et al. Prognostic significance of surgical-pathologic N1 disease in non-small cell carcinoma of the lung. Ann Thorac Surg 1999;67:1572-6.

7. Demir A, Turna A, Kocaturk C, et al. Prognostic significance of surgical-pathologic N1 lymph node involvement in non-small cell lung cancer. Ann Thorac Surg 2009;87:1014-22.

8. Maeshima AM, Tsuta K, Asamura H, et al. Prognostic implication of metastasis limited to segmental (level 13) and/or subsegmental (level 14) lymph nodes in patients with surgically resected nonsmall cell lung carcinoma and pathologic N1 lymph node status. Cancer 2012;118:4512-8.

9. Li ZM, Ding ZP, Luo QQ, et al. Prognostic significance of the extent of lymph node involvement in stage II-N1 nonsmall cell lung cancer. Chest 2013;144:1253-60.

10. Liu CY, Hung JJ, Wang BY, et al. Prognostic factors in resected pathological N1-stage II nonsmall cell lung cancer. Eur Respir J 2013;41:649-55.

11. Rena O, Boldorini R, Papalia E, et al. Metastasis to subsegmental and segmental lymph nodes in patients resected for non-small cell lung cancer: prognostic impact. Ann Thorac Surg 2014;97:987-92.

12. Mordant P, Pricopi C, Legras A, et al. Prognostic factors after surgical resection of $\mathrm{N} 1$ non-small cell lung cancer. Eur J Surg Oncol 2015;41:696-701.

13. Riquet $M$, Legras A, Mordant $P$, et al. Number of mediastinal lymph nodes in non-small cell lung cancer: a Gaussian curve, not a prognostic factor. Ann Thorac Surg 2014;98:224-31.

14. GREENBERG HB. Benign subpleural lymph node appearing as a pulmonary "coin" lesion. Radiology 1961;77:97-9.

15. Yokomise H, Mizuno H, Ike O, et al. Importance of intrapulmonary lymphnodes in the differential diagnosis of small pulmonary nodular shadows. Chest 1998;113:703-6.

16. Takenaka $M$, Uramoto $\mathrm{H}$, Shimokawa $\mathrm{H}$, et al. Discriminative features of thin-slice computed tomography for peripheral intrapulmonary lymph nodes. Asian J Surg 2013;36:69-73.

17. Boubia S, Barthes FL, Danel C, et al. Peripheral intrapulmonary lymph node metastases of non-small-cell lung cancer. Ann Thorac Surg 2004;77:1096-8.

18. Kirsh AL, Cushing SL, Chen EY, et al. Tertiary lymphoid organs in lymphatic malformations. Lymphat Res Biol 2011;9:85-92.

19. Aloisi F, Pujol-Borrell R. Lymphoid neogenesis in chronic inflammatory diseases. Nat Rev Immunol 2006;6:205-17.

20. Dieu-Nosjean MC, Giraldo NA, Kaplon H, et al. Tertiary 
lymphoid structures, drivers of the anti-tumor responses in human cancers. Immunol Rev 2016;271:260-75.

21. Kradin RL, Spirn PW, Mark EJ. Intrapulmonary lymph nodes: clinical, radiologic, and pathologic features. Chest 1985;87:662-7.

22. Murray JF. The normal lung: The basis for diagnosis and treatment of pulmonary disease. Philadelphia : W B Saunders Co, 1985.

23. Hattori A, Matsunaga T, Takamochi K, et al. Locoregional recurrence after segmentectomy for clinical-T1aN0M0 radiologically solid non-small-cell lung carcinoma. Eur J

Cite this article as: Riquet $M$, Pricopi C, Mangiameli G, Arame A, Badia A, Le Pimpec Barthes F. Diagnostic value of antineutrophil cytoplasmic antibodies in children with bronchiolitis obliterans. J Thorac Dis 2017;9(11):4286-4290. doi:10.21037/jtd.2017.10.119
Cardiothorac Surg 2017;51:518-25.

24. Stiles BM, Kamel MK, Nasar A, et al. The importance of lymph node dissection accompanying wedge resection for clinical stage IA lung cancer. Eur J Cardiothorac Surg 2017;51:511-7.

25. Akthar AS, Ferguson MK, Koshy M, et al. Limitations of PET/CT in the detection of occult N1 metastasis in clinical stage I(T1-2aN0) non-small cell lung cancer for staging prior to stereotactic body radiotherapy. Technol Cancer Res Treat 2017;16:15-21. 